\title{
Auditory brainstem response and late latency response in individuals with tinnitus having normal hearing
}

\author{
Sreeraj Konadath* ${ }^{*}$ Puttabasappa Manjula \\ Department of Audiology, All India Institute of Speech and Hearing, Mysuru, Karnataka State, India.
}

\begin{abstract}
Summary Tinnitus is a commonly encountered complaint in routine audiology practice. The pathophysiology and exact generation site of tinnitus is not precisely established. Auditory brainstem response $(A B R)$ and late latency response (LLR) findings in individuals with tinnitus show mixed results in the literature. Majority of studies have focused on individuals having tinnitus with peripheral hearing loss. The present study explores ABR and LLR characteristics among tinnitus patients with normal audiometric presentation; with no direct indication of any cochlear lesion. This study aims at characterizing the ABR and LLR findings in individuals with tinnitus having normal audiometric presentation. ABR and LLR waveform characteristics were recorded and compared between participants with tinnitus (Group 1) and those without tinnitus (Group 2). The ABR analysis indicated no significant differences in latency and amplitude between Groups 1 and 2. However, patients with tinnitus showed abnormally reduced absolute amplitudes of peaks I and V. LLR analysis indicated no significant differences in latency and amplitude between Groups 1 and 2 except enhanced amplitude of $P 1$. The reduced amplitude of peaks $I$ and $V$ along with normal absolute latencies of peaks I, III and V indicate that the origin of tinnitus is possibly due to reduced excitation of auditory nerve fibres arising from a peripheral hearing loss beyond $8 \mathrm{kHz}$. The P1 amplitude enhancement could be attributed to mechanism explaining central gain model; which suggests that central auditory structures recalibrates the mean firing rate, considering the reduced output from sensory structures, generating neural noise perceived as tinnitus.
\end{abstract}

Keywords: Auditory brainstem responses, late latency response, tinnitus, central gain mechanism

\section{Introduction}

Tinnitus is defined as a perceived sound with varied intensity, loudness and pitch in the absence of an external sound (1). The pathophysiology and exact generation site of tinnitus is not precisely established. Initially, the origin of tinnitus was attributed to peripheral auditory system $(2,3)$. Later, the involvement of central auditory structures was identified (4-6). Hazell (1995) proposed that tinnitus has its origin in the cochlear structures and/or within the brainstem as a weak signal that undergoes processes

Released online in J-STAGE as advance publication September 5, 2016.

*Address correspondence to:

Mr. Sreeraj Konadath, Department of Audiology, All India Institute of Speech and Hearing, Mysuru 570 006, Karnataka State, India.

E-mail: sreerajkonadath@aiishmysore.in like filtering and amplification before it is perceived at the cortical or sub-cortical level. This neural activity occurs in everyone; but, emotional issues as well as stress can enhance the perception of tinnitus (7). Various factors like outer and inner cochlear hair cell lesions, efferent auditory system impairment, cross-talk between the auditory nervous system fibers, ionic imbalances that occur within the cochlea, impaired functioning of cochlear neurotransmitters, various kinds of central auditory processing disorders or auditory neuropathy may lead to the perception of tinnitus (8). Thus, it can be assumed that multiple physiological factors across various levels of the auditory nervous system, to different degrees, can result in the development of tinnitus $(9,10)$.

About $10-25 \%$ of the adult population has prolonged tinnitus (11-14). 70-80\% of individuals with tinnitus have significant hearing difficulties (15). Even though tinnitus is commonly associated with hearing loss (16), it also exists among individuals with apparently 
normal hearing sensitivity (17). Hence, there might be a possibility of "hidden hearing loss" (18), wherein central auditory structures are involved in tinnitus generation. Even though based on real experiences, the individual with tinnitus believes that the sound is generated within the ear, the neurophysiological standpoint describes the symptom as a perception that happens in the cortical level and is reserved for sensorial modes (7). So, in addition to subjective audiological assessments, objective assessment plays a vital role in diagnosis of tinnitus.

Studies have been carried out to explore the phenomenon of tinnitus by means of auditory evoked potentials. Auditory evoked potentials help in understanding synchronous discharge of nerve fibers along the auditory pathway. The ABR are measured by means of scalp electrodes which pick up electrical potentials generated by the synchronous firing of neural populations within the brainstem. Thus, ABR provides an excellent method for assessing auditory function in a clinical set-up by recording the aggregate neural responses objectively and passively. Click evoked ABR has a wide-scale clinical application as a metric for evaluating auditory thresholds and identifying the neuropathologies (19). Certain ABR findings like abnormal waveform morphology, fluctuations in peaks III and $\mathrm{V}$, delayed transmission time and increased interaural latency difference of peak $\mathrm{V}$ etc. are observed in the case of individuals with tinnitus $(20,21)$. Thus, ABR helps in probing into the pathophysiology behind the origin of tinnitus.

The long latency responses (LLRs), which are generated from non-primary cortical areas measure the integrity of the auditory system beyond the level of brainstem. Studies have observed alterations in LLRs among individuals with tinnitus, like delayed N1 latency (22), and abnormal latency of P2 (23). With this background, to explore the role of higher auditory structures in the involvement of tinnitus, the evoked potentials play an integral role. Most of the studies concentrated on the assessment of tinnitus in individuals having elevated thresholds. Even though the prevalence of tinnitus is higher among individuals with hearing loss compared to those with normal hearing sensitivity, tracking its origin among the latter group is more obscure compared to the former one. Involvement of retrocochlear structures need to be examined to explore the tinnitus symptoms in such cases. Hence, this study was aimed at describing the findings of ABR and LLR in individuals with tinnitus having normal audiometric presentation.

\section{Materials and Methods}

\subsection{Participants}

The participants of the study were categorized into two groups. Group 1 was comprised of 20 individuals
(10 males, 10 females) having tinnitus as their primary complaint with normal hearing sensitivity, in the age range from 20 to 48 years (mean \pm S.D., $33.15 \pm 9.80$ ). Group 2 was comprised of 20 individuals (10 males, 10 females) with normal hearing in the age range from 18 to 22 years (mean \pm S.D., $20.50 \pm 1.79$ ).

All the participants in Group 1 and Group 2 had their air- and bone- conduction hearing thresholds within $20 \mathrm{~dB} \mathrm{HL}$ in the frequency range of $250 \mathrm{~Hz}$ to $8,000 \mathrm{~Hz}$. The speech identification score in the test ear was greater than $90 \%$. They had 'A' type tympanogram with acoustic reflexes at normal levels. The participants did not have any history of middle ear infections, use of oto-toxic drugs or significant noise exposure. The participants in Group I differed from Group II only in one aspect. The participants of Group I had continuous tinnitus, having a score of greater than 38 (i.e., moderate tinnitus) on Tinnitus Handicap Inventory (THI), whereas, the participants in Group 2 did not complain of tinnitus.

All the participants in Group 1 were individuals with a complaint of tinnitus who reported to the outpatient department of All India Institute of Speech and Hearing. Group 2 participants were selected from the staff and students cluster present at the same institute who had normal hearing and no complaint of tinnitus. Ethical clearance was obtained from the ethics committee of the institute before commencing this research work. Also, written informed consent was obtained from participants of both Groups for their inclusion in the study.

\subsection{Data collection}

As an initial step, a detailed case history was taken from participants of Group 1 to probe into the nature of the problem that the patient was facing, along with details of tinnitus perceived. Following this, a detailed audiological evaluation was carried out to check the airconduction thresholds between $250 \mathrm{~Hz}$ and $8,000 \mathrm{~Hz}$ and bone-conduction thresholds from $250 \mathrm{~Hz}$ to 4,000 Hz. The modified Hughson-Westlake procedure (24) was used to find out behavioral thresholds.

Further, speech reception threshold (SRT) was obtained using a paired-word list developed in the Department of Audiology. The Speech Identification Scores were obtained at 40 dB HL (ref. Speech Recognition Threshold) using Phonemically Balanced Kannada Word Test (25). Tympanograms were acquired using $226 \mathrm{~Hz}$ probe tone followed by measurement of acoustic reflex thresholds, both ipsilaterally and contralaterally at $500 \mathrm{~Hz}, 1,000 \mathrm{~Hz}, 2,000 \mathrm{~Hz}$ and 4,000 $\mathrm{Hz}$.

The THI (26) questionnaire was administered on participants in Group 1 to find out the details of tinnitus. The ABR and LLR recording was carried out using Biologic Navigator Pro Auditory Evoked Potential equipment (version 7.2.1) to meet the objectives of the 
Table 1. Acquisition and Stimulus parameters used for recording ABR and LLR

\begin{tabular}{lll}
\hline Parameters & ABR & LLR \\
\hline $\begin{array}{l}\text { Stimulus parameters } \\
\text { a. Type of stimulus }\end{array}$ & Clicks & \\
$\begin{array}{l}\text { b. Duration of stimulus } \\
\text { c. Polarity }\end{array}$ & $100 \mu \mathrm{sec}$ & $500 \mathrm{~Hz}$ tone burst of 500 Hz; Blackman window (2-0-2) \\
$\begin{array}{l}\text { e. Repetition rate } \\
\text { f. Intensity }\end{array}$ & $11.1 \mathrm{~Hz}$ & Rise/fall: $10 \mathrm{~ms}$; Plateau: $50 \mathrm{~ms}$ \\
Acquisition parameters & $70 \mathrm{~dB} \mathrm{nHL}$ & $1.1 / \mathrm{sec}$ \\
$\begin{array}{l}\text { a. Analysis time } \\
\text { b. Amplification }\end{array}$ & $15 \mathrm{~ms}$ & $70 \mathrm{~dB} \mathrm{nHL}$ \\
$\begin{array}{l}\text { c. Filter } \\
\text { d. Sweeps }\end{array}$ & $50,000 \times$ & $600 \mathrm{~ms}$ \\
e. Mode & $30 \mathrm{~Hz}$ to $3,000 \mathrm{~Hz}$ & $50,000 \mathrm{x}$ \\
f. Electrode montage & 1,500 & $1 \mathrm{~Hz}$ to $100 \mathrm{~Hz}$ \\
g. Electrode impedance & Monaural & 300 \\
$\quad$ Absolute & Vertical $(\mathrm{Fpz}, \mathrm{Cz}, \mathrm{M} 1 / \mathrm{M} 2)$ & Monaural \\
$\quad$ Inter electrode & $<5 \mathrm{k} \Omega$ & vertical $(\mathrm{Fpz}, \mathrm{Cz}, \mathrm{M} 1 / \mathrm{M} 2)$ \\
h. No. of channels & $<5 \mathrm{k} \Omega$ & $<5 \mathrm{k} \Omega$ \\
\hline
\end{tabular}

ABR, brainstem response; LLR, late latency response.

study. The stimulus and acquisition parameters used to record ABR and LLR are given in Table 1.

The participants were seated in a comfortable posture to ensure that the artifacts were minimal. The recording sites were cleaned using skin preparation gel. The silver chloride cup electrodes were placed on the test sites. Conduction paste was used to ensure good conductivity between skin and electrodes. After recording the ABR waveform, peaks I, III and V were marked manually by visual inspection by an experienced Audiologist. The latencies and absolute amplitudes of the aforementioned peaks were noted for further analysis. Later, LLR was recorded and the absolute amplitudes and latencies were noted for peaks P1, N1, P2 and N2. The same procedure was followed for recording the waveforms in both Groups.

\subsection{Data analysis}

Data collected from 40 ears (20 ears with tinnitus and 20 without tinnitus) were analyzed further using the statistical package for social sciences (SPSS) software version 21. Shapiro-Wilk's test was administered to check for normality of data. Because the data between group comparisons did not come under normal distribution, a non-parametric test was selected to check for differences between the groups. The variability is accounted for due to heterogeneity in the participants of the study.

\section{Results}

3.1. Comparison of absolute latency and amplitude of peak I, III and V between Group 1 and Group 2 for click evoked $A B R$

Descriptive statistics to calculate mean and standard deviation was carried out for Group 1 and Group 2.

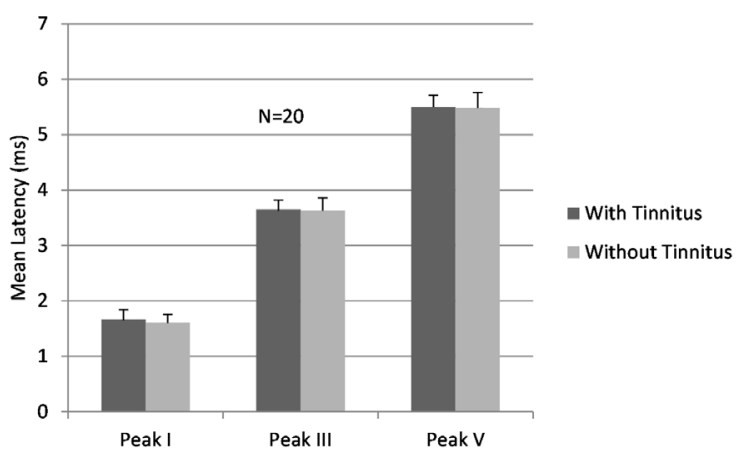

Figure 1. Mean and S.D. of latency of I, III and V peaks in Group 1 (with tinnitus) and Group 2 (without tinnitus).

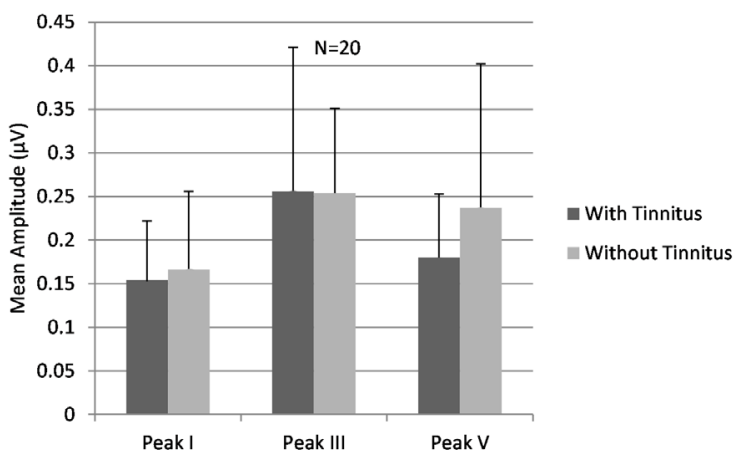

Figure 2. Mean and S.D. of amplitude of I, III and V peaks in Group 1 (with tinnitus) and Group 2 (without tinnitus).

At 11.1 repetitions per second, the mean latency and amplitude for I peak for the participants was $1.67 \mathrm{~ms}$ (S.D.-0.171) and $0.15 \mu \mathrm{V}$ (S.D.-0.068) respectively for Group 1; whereas it was $1.61 \mathrm{~ms}$ (S.D.-0.144) and 0.166 $\mu \mathrm{V}$ (S.D.-0.089) for Group 2. The mean latency and amplitude of III peak was $3.65 \mathrm{~ms}$ (S.D.-0.168) and 0.256 $\mu \mathrm{V}$ (S.D.-0.165) respectively for Group 1; whereas it was 3.63ms (S.D.-0.228) and $0.254 \mu \mathrm{V}$ (S.D.-0.097) for Group 2. The mean latency and amplitude for $\mathrm{V}$ peak, 
Table 2. $\mathrm{Z}$ values and level of significance for latency and amplitude of ABR and LLR

\begin{tabular}{|c|c|c|c|c|c|c|c|}
\hline & \multicolumn{3}{|c|}{ ABR Latency } & \multicolumn{4}{|c|}{ LLR Latency } \\
\hline & I peak & III peak & V peak & $\mathrm{P} 1$ & N1 & $\mathrm{P} 2$ & $\mathrm{~N} 2$ \\
\hline \multirow[t]{3}{*}{$\begin{array}{l}\text { Group } 1 \\
v s . \text { Group } 2\end{array}$} & $\begin{array}{l}1.128 \\
p>0.05\end{array}$ & $\begin{array}{l}0.950 \\
p>0.05\end{array}$ & $\begin{array}{l}0.448 \\
p>0.05\end{array}$ & $\begin{array}{l}0.323 \\
p>0.05\end{array}$ & $\begin{array}{l}0.217 \\
p>0.05\end{array}$ & $\begin{array}{l}1.354 \\
p>0.05\end{array}$ & $\begin{array}{l}0.604, \\
p>0.05\end{array}$ \\
\hline & \multicolumn{3}{|c|}{ ABR Amplitude } & \multicolumn{4}{|c|}{ LLR Amplitude } \\
\hline & I peak & III peak & V peak & $\mathrm{P} 1$ & N1 & $\mathrm{P} 2$ & $\mathrm{~N} 2$ \\
\hline $\begin{array}{l}\text { Group } 1 \\
\text { vs. Group } 2\end{array}$ & $\begin{array}{l}0.068 \\
p>0.05\end{array}$ & $\begin{array}{l}0.257 \\
p>0.05\end{array}$ & $\begin{array}{l}0.691 \\
p>0.05\end{array}$ & $\begin{array}{l}2.27 \\
p<0.05\end{array}$ & $\begin{array}{l}0.338 \\
p>0.05\end{array}$ & $\begin{array}{l}0.243 \\
p>0.05\end{array}$ & $\begin{array}{l}1.429 \\
p>0.05\end{array}$ \\
\hline
\end{tabular}

$\mathrm{ABR}$, brainstem response; LLR, late latency response.

was $5.50 \mathrm{~ms}$ (S.D.-0.213) and $0.180 \mu \mathrm{V}$ (S.D.-0.0728) respectively for Group 1, whereas it was $5.48 \mathrm{~ms}$ (S.D.0.280 ) and $0.223 \mu \mathrm{V}$ (S.D.-0.165) for Group 2. The mean latencies (with S.D.) and amplitudes of peaks I, III and $\mathrm{V}$ for the Group 1 and Group 2 is shown in Figure 1 and Figure 2 respectively.

Further, Mann Whitney U test was performed to look for any significant difference between the two groups in terms of latency and amplitude for the I, III and V peaks. Z and $p$ values obtained in the Mann Whitney U test are given in Table 2. Results in Table 2 indicate that only P1 amplitude showed a statistically significant $(p<0.05)$ difference between the groups among all the other parameters studied.

3.2. Comparison of absolute latency and amplitude of peaks P1, N1, P2 and N2 of LLR between Group 1 and Group 2

Descriptive statistics was carried out to find out the mean and standard deviation in LLR peaks for Group 1 and Group 2.The mean Latency and amplitude for the P1 peak for the participants is $47.33 \mathrm{~ms}$ (S.D.-11.29) and $2.80 \mu \mathrm{V}$ (S.D.-1.681) respectively for Group 1, whereas it was $49.79 \mathrm{~ms}$ (S.D.-14.041) and $1.543 \mu \mathrm{V}$ (S.D.-1.017) for Group 2. Peak N1 mean Latency and amplitude for the participants was $88.91 \mathrm{~ms}$ (S.D.-10.435) and -3.534 $\mu \mathrm{V}$ (S.D.-1.827) respectively for Group 1, whereas it was $89.56 \mathrm{~ms}$ (S.D.-14.368) and -3.573 $\mu \mathrm{V}$ (S.D.-2.449) for Group 2. For P2 peak, mean Latency and amplitude for the participants was $158.304 \mathrm{~ms}$ (S.D.-38.723) and $3.449 \mu \mathrm{V}$ (S.D.-1.774) respectively for Group 1, whereas it was $175.341 \mathrm{~ms}$ (S.D.-20.550) and $4.309 \mu \mathrm{V}$ (S.D.3.265) for Group 2. Further, for N2 peak, mean Latency and amplitude for the participants was $262.726 \mathrm{~ms}$ (S.D.39.444) and $-1.264 \mu \mathrm{V}$ (S.D.-1.1864) respectively for Group 1, whereas it was $251.860 \mathrm{~ms}$ (S.D.-33.441) and $-1.957 \mu \mathrm{V}$ (S.D.-0.948) for Group 2.

Mean latencies (with S.D.) and amplitudes of P1, N1, P2 and N2 peaks for Group 1 and Group 2 are shown in Figure 3 and Figure 4 respectively.

Mann Whitney $U$ test was performed to look for any significant differences between the groups in terms of

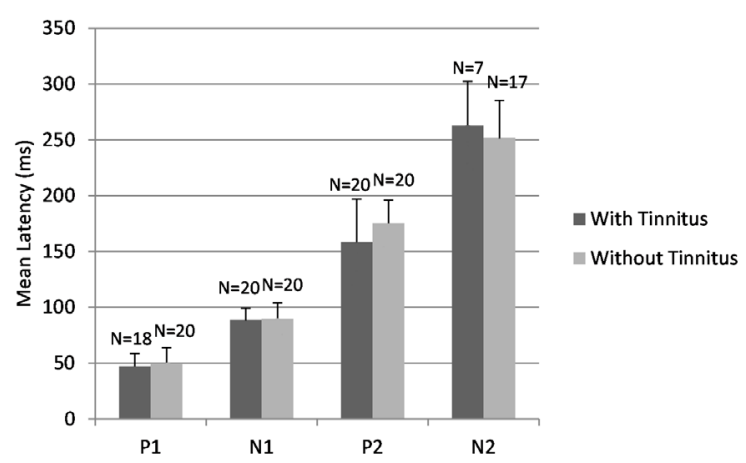

Figure 3. Mean and S.D. of latency of P1, N1, P2 and N2 peak in Group 1 (with tinnitus) and Group 2 (without tinnitus).

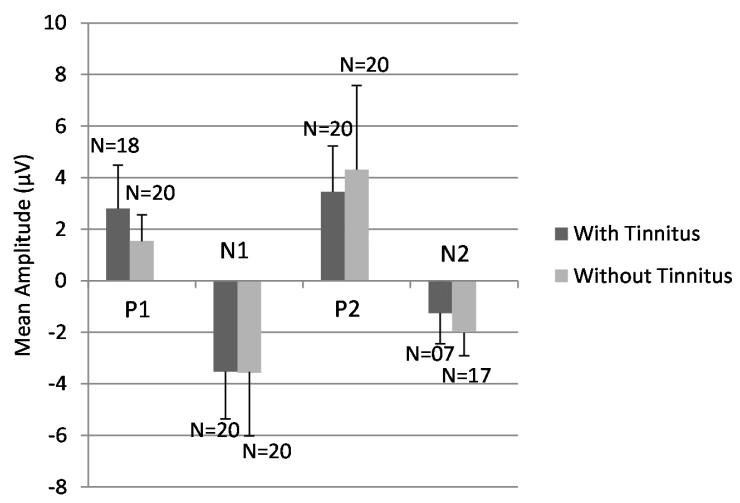

Figure 4. Mean and S.D. of amplitude of P1, N1, P2 and N2 peak in Group 1 (with tinnitus) and Group 2 (without tinnitus).

latency and amplitude for peaks P1, N1, P2 and N2. Z and $p$ values obtained in the Mann Whitney $U$ test are given in Table 2 .

The representative Waveforms of ABR and LLR for both groups are given in Figure 5 and 6 respectively. From Figure 5 it can be noted that there was no significant change in the ABR latency and Amplitude between the Groups. However, Figure 6 shows an increase in P1 amplitude in Group 1 LLR waveform.

\section{Discussion}

The aim of the present study was to characterize 

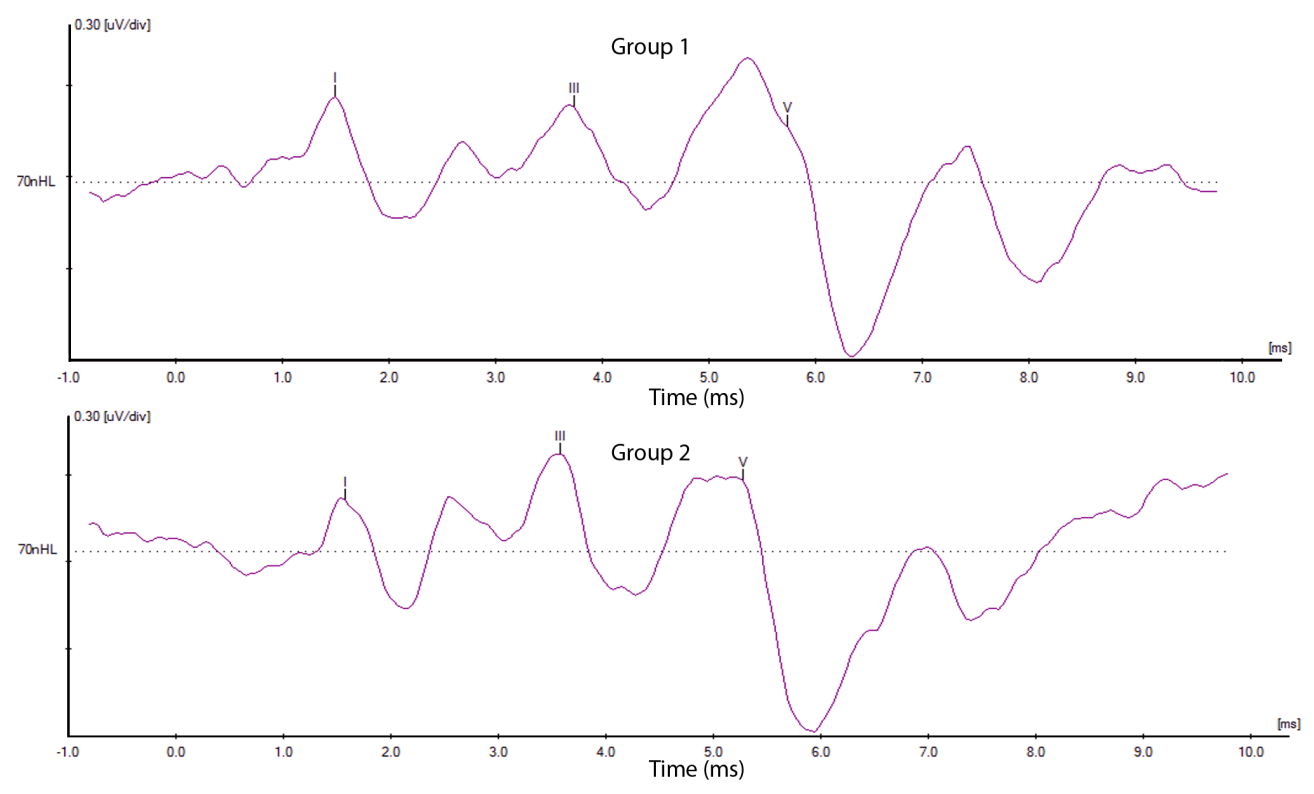

Figure 5. Representative waveform of ABR for Group 1 and Group 2. ABR, brainstem response.
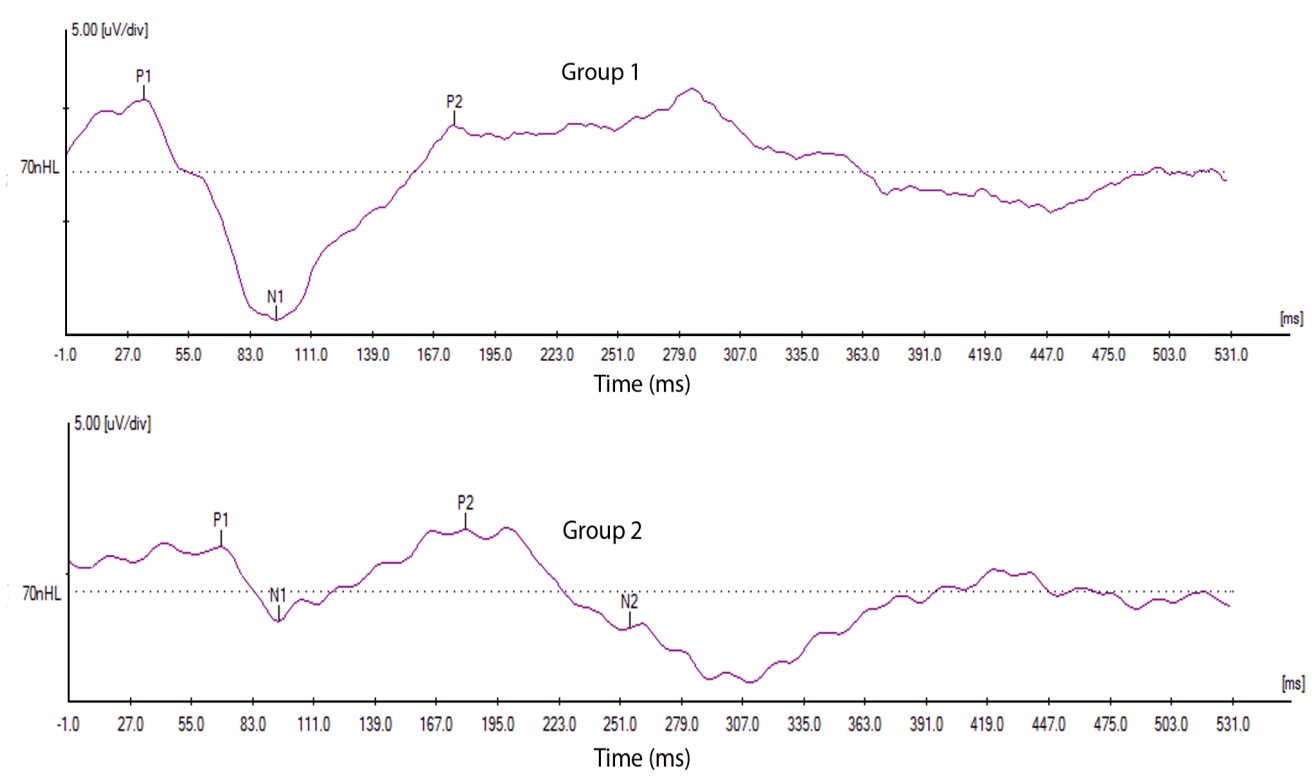

Figure 6. Representative waveform of LLR for Group 1 and Group 2. LLR, late latency response.

the findings of ABR and LLR in individuals with and without tinnitus having normal audiometric presentation. This would further target determining changes in the auditory structures that have occurred due to pathological changes of which tinnitus is a consequence.

The results from ABR indicated no significant differences in latency and amplitude between Group 1 and Group 2. However, participants with tinnitus (Group 1) showed abnormally reduced absolute amplitudes of peaks I and V. There are some possible explanations for the reduction in amplitude of peak I in tinnitus patients compared to individuals without tinnitus. The peak I of ABR is generated from the auditory nerve $(27,28)$.
Reduced amplitude of peak I could have resulted from a lesser contribution of responsiveness from auditory nerve fibers, or dys-synchrony in discharge of the auditory nerve fibers, or both (18). A similar, but detailed explanation is that, even if inner hair cells and auditory nerve fibers are intact, the excitability of the fibers might be reduced via lateral olivocochlear efferents which terminate on their endings. This perhaps may lead to the reduction in amplitude of Peak I (29). Another possibility is that; there might be damage to the higher-threshold auditory nerve fibers; but not to the lower-threshold fibers, which determine the behavioral threshold. This conclusion is from an animal study in which, after recovering from a temporary threshold shift, 
acoustically over-exposed mice presented with a normal set of inner hair cells; but had degeneration of auditory nerve fibers (30). Further, the lesser amplitude of peaks Peak I and V could be due to peripheral hearing loss at frequency regions in the cochlea beyond $8 \mathrm{kHz}(31)$. The findings of this study support the fact that peripheral loss $(3,32)$ (not observed in routine audiological evaluation), occurring due to hair cell damage could be a probable reason for reduced output from nerve fibers at the brainstem level. When absolute latencies are taken into account, no statistically significant difference was found between the two groups. This is similar to the findings by Barnea, Attias, Gold and Shahar (1990) (33), wherein, absolute latencies of peaks I, III and V were within normal limits for individuals with normal hearing and tinnitus. Tinnitus with a normal conventional audiogram does not indicate an appreciable lesion at the level of the brainstem. The reduced amplitude of peaks I and $\mathrm{V}$ along with normal absolute latencies of peaks I, III and V in the present study indicate that the underlying factor for the origin of tinnitus is possibly due to reduced excitation of auditory nerve fibers. The findings also can be due to existence of peripheral hearing loss beyond $8 \mathrm{kHz}$, which was not assessed in this study.

The results of LLR indicated that there was no significant difference in the latency and amplitude between Group 1 and Group 2, except for enhanced amplitude of the P1 peak in Group 2. The P1 component of LLR is generated from the pedunculopontine tegmental nucleus, which is a cholinergic sub-division of reticular formation that receives auditory input (34). The increased amplitude of the P1 peak in Group 2 could be attributed to a central gain adaptation mechanism which, when confronted with decreased peripheral input, boosts the neural gains to increase spontaneous activity to a point where it is perceived as sound (35). The involvement of central auditory structures in the generation and perception of tinnitus is evident in the literature (36-38).

Peripheral damage at the level of the cochlea leads to reduced auditory input. Output from central auditory neurons is modulated in response to incoming alterations in signals from the periphery (39). The reduced output from the periphery leads to sensory deprivation, which in turn leads to altered neural activity in various areas of the brain (40). Evidence suggests that this kind of altered neural activity is seen at the level of the inferior colliculus and auditory cortex (41-43). The central gain model suggests that the central auditory structures recalibrate the mean firing rate considering the reduced output from the sensory structures, generating neural noise perceived as tinnitus (44).

\section{Conclusion}

The present study tried to explore the sensorineural correlates of tinnitus among tinnitus patients with normal audiometric thresholds. The electrophysiological investigations using ABR and LLR revealed considerable differences in findings between individuals with normal hearing with and without tinnitus. The abnormally reduced amplitudes of peaks I and V in ABR could be attributed to reduced excitation of auditory nerve fibers. The findings also can be attributed to existence of peripheral hearing loss beyond $8 \mathrm{kHz}$, which needs to be explored. The increased amplitude of the P1 component of LLR in individuals with tinnitus could be attributed to a central gain adaptation mechanism which, when confronted with decreased peripheral input, boosts neural gains to increase spontaneous activity to a point where it is perceived as sound.

\section{Acknowledgements}

Authors acknowledge Dr. S. R. Savithri, Director, All India Institute of Speech and Hearing, Mysuru and HOD Audiology for permitting to publish this research work.

\section{References}

1. Møller AR. Tinnitus: Presence and future. Prog Brain Res. 2007;166:3-16.

2. Salvi RJ, Ahroon WA. Tinnitus and neural activity. J Speech Hear Res. 1983; 26:629-632.

3. Eggermont JJ. On the pathophysiology of tinnitus; a review and a peripheral model. Hear Res. 1990; 48:111123.

4. Norena A, Cransac H, Chery-Croze S. Towards an objectification by classification of tinnitus. Clin Neurophysiol. 1999; 110:666-675.

5. Mühlnickel W, Elbert T, Taub E, Flor H. Reorganization of auditory cortex in tinnitus. Proc Natl Acad Sci U S A. 1998; 95:10340-10343.

6. Hoke M, Feldmann H, Pantev C, Lütkenhöner B, Lehnertz $\mathrm{K}$. Objective evidence of tinnitus in auditory evoked magnetic fields. Hear Res. 1989; 37:281-286.

7. Hazell JWP. Models of tinnitus: Generation, perception, clinical implications. In: Mechanisms of Tinnitus (Vernon JA, Moller AR, eds.). Allyn and Bacon, Boston, USA, 1995; pp. 57-72.

8. Estola-Partanen M. Muscular tension and tinnitus: An experimental trial of trigger point injections on tinnitus: Tampere University Press; 2000.

9. Hazell JW, Jastreboff PJ. Tinnitus. I: Auditory mechanisms: A model for tinnitus and hearing impairment. J Otolaryngol. 1990; 19:1-5.

10. Baguley DM. Mechanisms of tinnitus. Br Med Bull. 2002; 63:195-212.

11. Heller AJ. Classification and epidemiology of tinnitus. Otolaryngol Clin North Am. 2003; 36:239-248.

12. Khedr EM, Ahmed MA, Shawky OA, Mohamed ES, El Attar GS, Mohammad KA. Epidemiological study of chronic tinnitus in Assiut, Egypt. Neuroepidemiology. 2010; 35:45-52.

13. Baguley D, McFerran D, Hall D. Tinnitus. Lancet. 2013; 382:1600-1607.

14. Langguth B, Kreuzer PM, Kleinjung T, De Ridder D. 
Tinnitus: Causes and clinical management. Lancet Neurol. 2013; 12:920-930.

15. Vernon JA, Meikle MB. Tinnitus masking. In: Tinnitus Handbook (Tyler RS, eds.). Singular Thomson Learning, San Diego, USA, 2000; pp. 313-356.

16. McCormack A, Edmondson-Jones M, Fortnum H, Dawes P, Middleton H, Munro KJ, Moore DR. The prevalence of tinnitus and the relationship with neuroticism in a middleaged UK population. J Psychosom Res. 2014; 76:56-60.

17. Barnea G, Attias J, Gold S, Shahar A. Tinnitus with normal hearing sensitivity: Extended high-frequency audiometry and auditory-nerve brain-stem-evoked responses. Audiology. 1990; 29:36-45.

18. Schaette R, McAlpine D. Tinnitus with a normal audiogram: Physiological evidence for hidden hearing loss and computational model. J Neurosci. 2011; 31:1345213457.

19. Starr A, Picton TW, Sininger Y, Hood LJ, Berlin CI. Auditory neuropathy. Brain. 1996; 119:741-753.

20. Shulman A, Seitz MR. Central tinnitus - diagnosis and treatment. Observations simultaneous binaural auditory brain responses with monaural stimulation in the tinnitus patient. Laryngoscope. 1981; 91:2025-2035.

21. Gabr TA. Auditory brainstem response audiometry in tinnitus patients. Egyptian Journal of Ear, Nose, Throat and Allied Sciences. 2011; 12:115-120.

22. Attias J, Furman V, Shemesh Z, Bresloff I. Impaired brain processing in noise-induced tinnitus patients as measured by auditory and visual event-related potentials. Ear Hear. 1996; 17:327-333.

23. Santos Filha VA, Matas CG. Late Auditory evoked potentials in individuals with tinnitus. Braz J Otorhinolaryngol. 2010; 76:263-270.

24. Carhart R, Jerger JF. Preferred method for clinical determination of pure-tone thresholds. Journal of Speech and Hearing Disorders. 1959; 24:330-345.

25. Yathiraj A, Vijayalakshmi CS. Phonemically Balanced Word List in Kannada. Developed in Department of Audiology, All India Institute of Speech and Hearing, Mysore, 2005.

26. Newman CW, Sandridge SA, Bolek L. Development and psychometric adequacy of the screening version of the tinnitus handicap inventory. Otol Neurotol. 2008; 29:276281.

27. Buchwald JS, Huang C. Far-field acoustic response: Origins in the cat. Science. 1975; 189:382-384.

28. Møller AR, Jannetta P, Bennett M, Møller MB. Intracranially recorded responses from the human auditory nerve: New insights into the origin of brain stem evoked potentials (BSEPs). Electroencephalogr Clin Neurophysiol. 1981; 52:18-27.

29. Gu JW, Herrmann BS, Levine RA, Melcher JR. Brainstem auditory evoked potentials suggest a role for the ventral cochlear nucleus in tinnitus. J Assoc Res Otolaryngol. 2012; 13:819-833.

30. Kujawa SG, Liberman MC. Adding insult to injury: Cochlear nerve degeneration after "temporary" noiseinduced hearing loss. J Neurosci. 2009; 29:14077-14085.

31. Kehrle HM, Granjeiro RC, Sampaio AL, Bezerra R, Almeida VF, Oliveira CA. Comparison of auditory brainstem response results in normal-hearing patients with and without tinnitus. Arch Otolaryngol Head Neck Surg. 2008; 134:647-651.

32. Salvi RJ, Ahroon WA. Tinnitus and neural activity. J Speech Hear Res. 1983; 26:629-632.

33. Barnea G, Attias J, Gold S, Shahar A. Tinnitus with normal hearing sensitivity: Extended high-frequency audiometry and auditory-nerve brain-stem-evoked responses. Audiology. 1990; 29:36-45.

34. Harrison JB, Woolf NJ, Buchwald JS. Cholinergic neurons of the feline pontomesencephalon. I. Essential role in 'wave A'generation. Brain Res. 1990; 520:43-54.

35. Parra LC, Pearlmutter BA. Illusory percepts from auditory adaptation. J Acoust Soc Am. 2007; 121:1632-1641.

36. Norena A, Cransac H, Chery-Croze S. Towards an objectification by classification of tinnitus. Clin Neurophysiol. 1999; 110:666-675.

37. Mühlnickel W, Elbert T, Taub E, Flor H. Reorganization of auditory cortex in tinnitus. Proc Natl Acad Sci U S A. 1998; 95:10340-10343.

38. Hoke M, Feldmann H, Pantev C, Lütkenhöner B, Lehnertz $\mathrm{K}$. Objective evidence of tinnitus in auditory evoked magnetic fields. Hear Res. 1989; 37:281-286.

39. Middleton JW, Kiritani T, Pedersen C, Turner JG, Shepherd GM, Tzounopoulos T. Mice with behavioral evidence of tinnitus exhibit dorsal cochlear nucleus hyperactivity because of decreased GABAergic inhibition. Proc Natl Acad Sci U S A. 2011; 108:7601-7606.

40. Syka J. Plastic changes in the central auditory system after hearing loss, restoration of function, and during learning. Physiol Rev. 2002; 82:601-636.

41. Robinson BL, McAlpine D. Gain control mechanisms in the auditory pathway. Curr Opin Neurobiol. 2009; 19:402407.

42. Rabinowitz NC, Willmore BD, Schnupp JW, King AJ. Contrast gain control in auditory cortex. Neuron. 2011; 70:1178-1191.

43. Willmore BD, Cooke JE, King AJ. Hearing in noisy environments: Noise invariance and contrast gain control. J Physiol. 2014; 592:3371-3381.

44. Auerbach BD, Rodrigues PV, Salvi RJ. Central gain control in tinnitus and hyperacusis. Front Neurol. 2014; 5:206.

(Received June 29, 2016; Revised August 12, 2016; Accepted August 15, 2016) 